\title{
Instrumented Vickers microindentation of alumina-based materials
}

\author{
S. Bueno and C. Baudin ${ }^{\text {a) }}$ \\ Instituto de Cerámica y Vidrio, Consejo Superior de Investigaciones Cientificas; Campus de \\ Cantoblanco, 28049 Madrid, Spain
}

(Received 17 May 2005; accepted 23 September 2005)

\begin{abstract}
The adequacy of instrumented Vickers depth-sensing microindentation to determine Young's modulus of alumina-based ceramics was analyzed. Monophase alumina materials and alumina +10 vol\% aluminium titanate composites, with different microstructures, were tested to determine the effect of microcracking. The load-depth penetration of the indenter curves together with the observation of the imprints by scanning electron microscopy were used to analyze the behavior of the materials. Maximum stiffness was determined from the derivatives of the load-depth curves during unloading. The areas of the imprints measured optically were more representative of the behavior of the materiais than the areas calculated from depth-penetration measurements. The formation of microcracks affected the shape of the unloading portion of the curves. Significant differences between the values of Young's modulus determined for different materials and definite relationships between the microstructural parameters of the materials and the Young's modulus were found.
\end{abstract}

\section{INTRODUCTION}

Vickers indentation at the micrometer level is currently used to evaluate hardness of ceramics, and it is a very useful tool to determine toughness when only small volumes of material are available. ${ }^{1,2}$ Also, differences in the development of microindentation cracks in the different layers of layered materiais, in which the thickness of the layers is in the order of hundreds of microns, are being investigated as a means to evaluate residual stresses through the layers. ${ }^{3,4}$

With the advent of instrumented indentation techniques, first developed as a depth-sensing microindenter by a group working at the Baikov Institute of Metallurgy in Moscow, ${ }^{5}$ much research has been devoted to the use of sub-micrometer and nanometer indentation to determine the behavior of materials, not only in the plastic but also in the elastic regime. In particular, data for hardness $H$ and Young's modulus $E$ are obtained from one complete cycle of loading and unloading in the nanometer range, with sharp indenters of Vickers or Berkovich geometries $^{6-18}$ and spherical indenters. ${ }^{8.18-20}$ To a lesser extent, indentation techniques in the micrometer level have also been proposed to analyze the mechanical behavior of ceramics and metals using spherical ${ }^{21-24}$ and Vickers ${ }^{23-25}$ indenters.

\footnotetext{
${ }^{a}$ Address all correspondence to this author.

e-mail: cbaudin@icv.csic.es

DOI: 10.1557/JMR.2006.0007
}

The schematic representation of load versus indenter penetration depth during the whole loading-unloading cycle is shown in Fig. 1(a). Deformation during loading is assumed to be both elastic and plastic in nature as the permanent hardness impression forms and during unloading it is assumed that only the elastic displacements are recovered. ${ }^{18}$ The key experimental parameters are the peak load $P_{\max }$, the depth at peak load $h_{\max }$, and the elastic unloading stiffness $S=\mathrm{d} P / \mathrm{d} h$, defined as the slope of the upper portion of the unloading curve.

Determination of the Young's modulus relies on its relationship to contact area $A$ and $S$ through ${ }^{18}$

$$
S=\mathrm{d} P / \mathrm{d} h=k \cdot 2 \cdot \pi^{-1 / 2} \cdot E_{\mathrm{r}} \cdot A^{1 / 2},
$$

where $E_{\mathrm{r}}$ is the reduced elastic modulus, which accounts for elastic displacements in both the sample and the indenter and is defined by

$$
1 / E_{\mathrm{r}}=\left(1-v^{2}\right) / E+\left(1-v_{i}^{2}\right) / E_{\mathrm{i}},
$$

being $E$ and $E_{\mathrm{i}}$ and $v$ and $\nu_{\mathrm{i}}$ the Young's modulus and Poisson's ratio for the sample and the indenter, respectively.

The constant $k$ is a correction factor that evaluates deviations from the case of small deformations of an elastic material by a rigid axisymmetric punch of smooth profile for which $\mathrm{k}=1$. As simple elastic procedures ${ }^{18}$ give $\mathbf{k}$ values close to 1 for Vickers indenters $(\mathbf{k}=$ 1.0055), and it is taken as 1 in most works, this latter value will be used here for calculations.

From Eq. (1), contact stiffness and contact area at peak load are the two parameters required to calculate the 

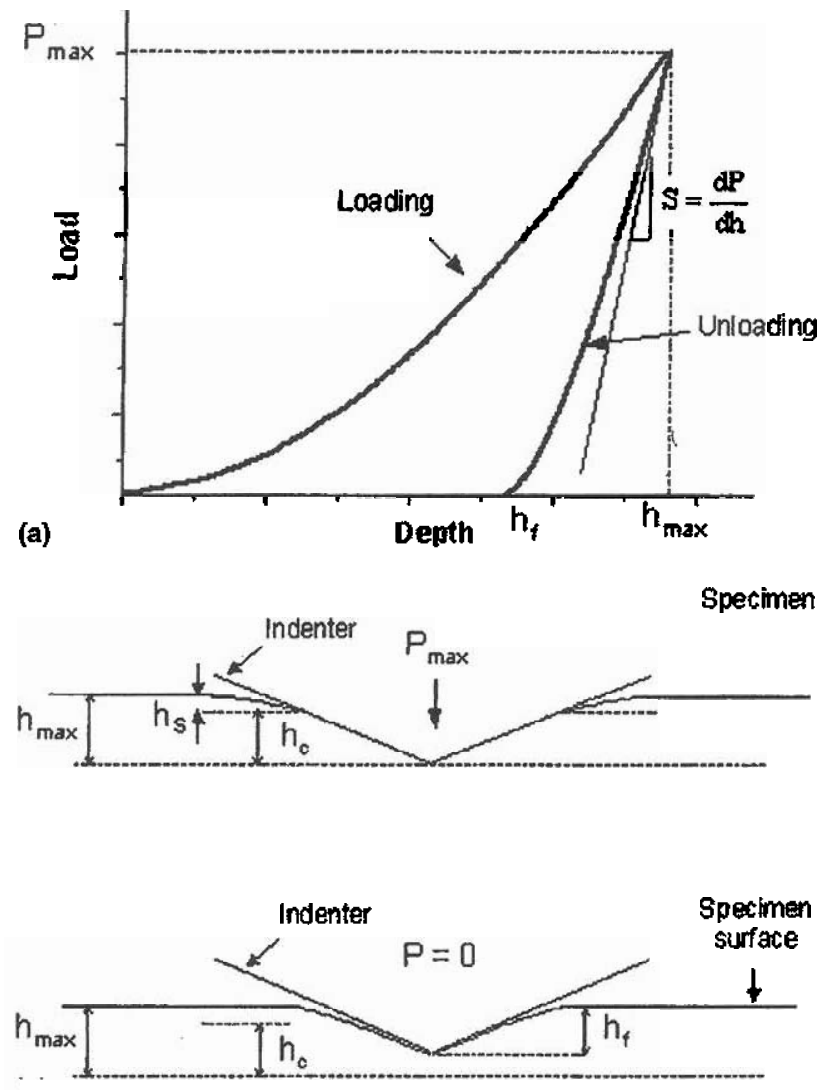

(b)
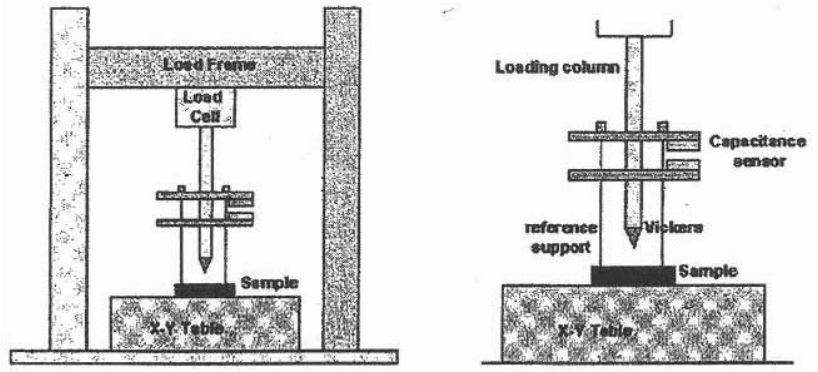

(c)

FIG. 1. (a) Schematic representation of the relationship load-indenter penetration depth obtained during a whole loading-unloading cycle. $P_{\max }$ is peak load, $h_{\max }$ is maximum depth, $h_{\mathrm{f}}$ is final depth, and $S$ is contact stiffness. (b) Schematic representation of the indenter and the specimen surface when the indenter is pressed into the material at maximum load $P_{\max }$ and in the unloaded state, $P=0$. (c) Schematic representation of the instrumented microindenter used in this work showing the detail of the capacitive device for measurement of penetration depth.

Young's modulus of the specimen. The contact stiffness is determined from the general relationship between load and penetration depth during the unloading portion of the cycle given by

$$
P=\alpha_{0} \cdot\left(h-h_{\mathrm{f}}\right)^{\mathrm{m}},
$$

where $h_{\mathrm{f}}$ is the final depth [Fig. 1(a)] and $\alpha_{0}$ and $m$ are fitting constants.

Initial data by Doerner and $\mathrm{Nix}^{26}$ suggested $m=1$ in Eq. (3) for most materials, so the flat punch approximation could be used to determine stiffness. Nevertheless, detailed observation of the unloading curves ${ }^{5-13,22,23,25}$ showed that this assumption is not exact for a number of materials, especially for hard ones such as ceramics, for which the contact stiffness diminishes immediately and continuously as the specimen is unloaded. This behavior is better described by power laws, such as Eq. (3) in which the exponent $m$ depends not only on the indenter geometry but also on the material tested. To account for this behavior, Oliver and Pharr ${ }^{6}$ proposed to use the fit of the unloading data to a power law to determine the contact stiffness at peak load.

The contact area is geometrically related to the vertical distance along which the contact between the indenter and the specimen surface is made, called the contact depth $h_{c}$, through the shape function of the indenter. This relationship cannot be modeled on the basis of the elastic contact analysis for elastic-plastic materials in which significant pileup occurs. ${ }^{18}$ For elastically deformed materials, attempts to relate directly the maximum depth $h_{\max }$ to the contact area $A$ were unsuccessful due to the deflection of the surface at the contact perimeter, ${ }^{5,6,10,25}$ as schematically shown in Fig. 1(b). For these materials, the amount of sinking-in $h_{\mathrm{s}}$ is given by ${ }^{18}$

$$
h_{\mathrm{s}}=\epsilon \cdot \frac{P_{\max }}{S}
$$

where $\epsilon$ is a constant that depends on the geometry of the indenter.

Then, the depth along which contact is made between the indenter and the specimen $h_{\mathrm{c}}$ [Fig. 1(b)], is related to the maximum depth $h_{\max }$ by

$$
h_{\mathrm{c}}=h_{\max }-\epsilon \cdot \frac{P_{\max }}{S} \text {. }
$$

For curves corresponding to punch geometries of flat cylinders [ $m=1$ in Eq. (3)], $\epsilon=1$ and the value of $h_{c}$ is calculated from the intersection with the $x$ axis of a straight line with slope equal to the maximum slope in the $P-h$ curve and passing through the point of maximum stiffness. According to Oliver and Pharr, ${ }^{18}$ unloading curves for a wide range of materials and punch geometries are best approximated by an indenter that behaves by a paraboloid of revolution $(m=1.5)$, and the geometric constant corresponding to this geometry $\epsilon=0.75$ was recommended by these authors as standard value for analysis.

Alternatively, the contact area can be determined from the diagonals of the residual imprint, considering that there is no elastic recovery at the diagonals and that the 
projected contact area under load is a perfect square. ${ }^{25}$ This parameter $A_{\text {op }}$ is usually called the true projected contact area.

Cook and Pharr ${ }^{27}$ have found that the large cracks originated in the samples during testing, as occurs for sharp indenters and relatively high loads in ceramics and glasses, ${ }^{27,28}$ do not affect the load-depth curve in Fig. 1(a). On the contrary, a significant load drop associated with a displacement of the indenter was found when the indentation was reloaded due to the extension of lateral cracks accompanied by the ejection of pieces of the surface.

Lateral crack formation in ceramics occurs well after the initiation of unloading and therefore will not have any effect on the initial part of the unloading curve used to determine stiffness. Conversely, as the characteristics of the contact would be highly affected by microstructural factors, it is probable for microcrack development under the indenter to modify the initial part of the unloading curve. As a basic statement, the larger the similarity between the imprint size and the microstructure of the materials, the more measurements will be influenced by local properties.

In this work, the adequacy of instrumented Vickers depth-sensing microindentation at low loads to determine Young's modulus of ceramics with different grain sizes and in which different levels of residual stresses are present is analyzed. The special conditions involved in Vickers indentation, i.e., highly concentrated loads in small volumes, should lead to different levels of microcracking, as a function of residual stresses and grain size. The main interest of the work is that, as emphasized by Baker, ${ }^{5}$ depth-sensing indentation is one of the few methods in which very small volumes of material can be deformed in a controlled way to determine mechanical properties.

Six dense alumina $\left(\mathrm{Al}_{2} \mathrm{O}_{3}\right)$ and alumina-aluminium titanate $\left(\mathrm{Al}_{2} \mathrm{O}_{3}-\mathrm{Al}_{2} \mathrm{TiO}_{5}\right)$ materials with different microstructures were developed for the investigation. In all of them, residual stresses were expected to be present due to the thermal expansion anisotropy of alumina and/or thermal expansion mismatch between alumina and aluminium titanate. ${ }^{29-32}$ Three of them were monophase aluminas, with different grain sizes well below that for spontaneous microcracking during cooling from the sintering temperature $(\cong 100 \mu \mathrm{m}){ }^{31}$ The other three were alumina $+10 \mathrm{vol} \%$ aluminium titanate composites, for which higher levels of residual stresses than those acting in the alumina materials developed. Two composites had the average size of the aluminiurn titanate grains of the same order as the critical one for spontaneous cracking of the alumina matrix. ${ }^{32}$

The analysis of the derivative of the experimental load-depth curves during unloading is proposed as a reliable method to determine maximum stiffness $S$ and the corresponding Young's modulus values. These latter values are compared with those determined by a dynamic method, which involves a much lower deformation level in the materials during testing.

Penetration depth of the indenter has been directly determined using a capacitance sensor in the loading column in which the indenter is fixed and which measures the penetration of the indenter punch taking the surface of the sample as reference [Fig. 1(c)]. Also, a peak load hold period was included in the loading sequence to diminish time-dependent effects during unloading. An alternative method proposed to diminish these effects, which may be used in the nano and sub-micrometer ranges, is to perform multiple loadings to assure reversibility. ${ }^{6}$ Such a method is not applicable in this case, as lateral cracks are expected to develop and give rise to a discontinuity in the $P$ - $h$ curve as discussed above.

\section{EXPERIMENTAL}

Alumina materials (A) and alumina-10 vol\% aluminium titanate composites (A10AT), were obtained using $\mathrm{Al}_{2} \mathrm{O}_{3}$ (Condea, HPA05, Houston, TX) and $\mathrm{TiO}_{2}$ (Merck, 808, Darmstadt, Germany) as starting powders. In previous works, ${ }^{32-33}$ the processing conditions to fabricate dense and completely reacted alumina-aluminium titanate composites with a homogeneous dispersion of the second phase, using isostatic pressing and colloidal filtration techniques, were established. Compacts of monophase alumina and one composite $\left(90 \times 50 \times 12 \mathrm{~mm}^{3}\right)$ were prepared by attrition milling of $\mathrm{Al}_{2} \mathrm{O}_{3}$ and previously reacted $\mathrm{Al}_{2} \mathrm{TiO}_{5}$ powders and isostatic pressing $(200 \mathrm{MPa})$. These materials were sintered at $1500^{\circ} \mathrm{C}$ for $1 \mathrm{~h}$, using $5^{\circ} \mathrm{C}^{-1}$ as heating and cooling rates. For the materials obtained by colloidal filtration, stable suspensions of a mixture of $\mathrm{Al}_{2} \mathrm{O}_{3}$ and $\mathrm{TiO}_{2}$ to a solid loading of 50 vol\% $(80 w 5 \%)$ were prepared by ball milling and green compacts of about $70 \times 70 \times 10 \mathrm{~mm}^{3}$ were made by colloidal filtration on plaster of Paris molds. The sintering was performed using heating and cooling rates of $2{ }^{\circ} \mathrm{C} \mathrm{min}-1$ and a dwell of $4 \mathrm{~h}$ at $1200^{\circ} \mathrm{C}$ during the heating. Two different high-temperature dwells were used to reach different levels of grain growth, $2 \mathrm{~h}$ at $1450^{\circ} \mathrm{C}$ (naterials A1450 and A10AT-1450) and $3 \mathrm{~h}$ at $1550^{\circ} \mathrm{C}$ (materials A1550 and A10AT-1550). In the following, for easier identification, the sintered samples have been labeled using $P$ for materials processed by isostatic pressing (P-A, PA10AT) and $S$ for materials processed by colloidal filtration (S-A1450, S-A1550, S-A10AT-1450, and S-A10AT-1550). The densities of the sintered compacts were determined by the Archimedes method and related to the theoretical density calculated from the ASTM Files 42-1468 and 26-0040 for $\alpha-\mathrm{Al}_{2} \mathrm{O}_{3}$ and $\beta-\mathrm{Al}_{2} \mathrm{TiO}_{5}$, respectively.

Microstructural characterization was performed by field emission scanning electron microscopy (FE-SEM, 
Hitachi, S-4700, Tokyo, Japan) on polished and thermally etched $\left(20^{\circ} \mathrm{C}\right.$ below the sintering temperature for $1 \mathrm{~min}$ ) surfaces. The average grain size was determined by the linear intercept method considering at least 200 grains for each phase.

Samples were machined from the sintered blocks into bars of $25 \times 2 \times 2.5 \mathrm{~mm}^{3}$ for the determination of the dynamic Young's modulus from the resonance frequency of bars tested in bending by impact (Grindosonic, Lemmens, Leuven, Beigium). Reported values are the average of five determinations, and errors are the standard deviations.

The indentation tests were performed on $4 \times 6 \mathrm{~mm}^{2}$ surfaces of samples $4 \mathrm{~mm}$ high, diamond polished to $3 \mu \mathrm{m}$, and finished with colloidal alumina, using a specially developed electromechanical indentation device [Microtest, Madrid, Spain, Fig. 1(c)] in which the sample is placed on an $X-Y$ table $\left(5 \times 5 \mathrm{~cm}^{2}\right)$. The indenter is a diamond Vickers pyramid (angle $136^{\circ}$ and area-depth ratio $A=24.5 h^{2}$ ) fixed at the loading column placed, together with the load cell, at the central part of the loading frame. The indentation depth is determined by a capacitance displacement gauge mounted in the loading column immediately above the indentation tip. This capacitance device, which can take as a reference position the surface of the sample or the surface of the $X-Y$ table, allows the detection of changes in the relative displacement in the range of $0.01 \mu \mathrm{m}$.

Loading was performed using constant rate $(0.1 \mathrm{~mm} / \mathrm{min})$ for the displacement of the load frame, up to $50 \mathrm{~N}$. Then, the load was held for $10 \mathrm{~s}$, and finally, unloading was performed at the same rate. For all the tests, the values of time, load, displacement of the load frame, and penetration depth were continuously recorded.

Optical microscopy (Carl-Zeiss H-P1, Oberkochen, Germany) was performed on the indented samples, and the projected areas of the residual impressions were calculated from the length of the diagonal $2 a$, measured with an accuracy of $\pm 2 \mu \mathrm{m}$. The indentations were also observed in a field emission scanning electron microscope (FE-SEM, Hitachi, S-4700, Tokyo, Japan) within $1 \mathrm{~h}$ after unloading.

At least five tests were carried out for each material. Average values for all reported parameters and the standard deviations are given as results.

To calculate Young's modulus using Eq. (1), it is necessary to assume a value for the Young's modulus of the indenter, which, as signaled by Menick et al., ${ }^{10}$ affects the obtained values. In this work, a value of $1000 \mathrm{GPa}$ was considered, but a range between 800 and $1200 \mathrm{GPa}$ is given in the literature for diamond, which might give a difference of about 5\% for the range of Young's modulus values considered here ( $\cong 200$ to $300 \mathrm{GPa}$ ).

As will be discussed below, we have observed the unsuitability of the methods proposed by Doemer and
$\mathrm{Nix}^{26}$ and Oliver and Pharr ${ }^{6}$ to determine stiffness in most of the materials studied here. Therefore, the derivative of the experimental curves during the unloading cycle was directly analyzed. To check the validity of the analysis and the performance of the apparatus, a Vickers hardness standard specimen of steel (727 HV1-MPA 37519.74, Leco, St. Joseph, MD was tested. In Fig. 2, characteristic experimental curves for samples of this material [Fig. 2(a)], a characteristic derivative of the experimental data at the unloading portion [Fig. 2(b)], and a characteristic imprint [Fig. 2(c)] are shown. Curves for different tests were fairly coincident [Fig. 2(a)]. The areas of the residual imprints calculated from the diagonals, coincident for five different determinations, were $6200 \mathrm{\mu m}^{2}$. The corresponding Vickers hardness value was $7.4 \mathrm{GPa}$. In all cases, maximum stiffness (14.6 \pm $0.2 \mathrm{~N} / \mu \mathrm{m}$ ) occurred at the initiation of unloading. From this value and the area of the residual imprint determined optically, the obtained Young's modulus value was $182 \pm$ $2 \mathrm{GPa}$. Vickers hardness and Young's modulus were in agreement with the standard requirements $\left(H_{\mathrm{v}}=\right.$ $7.27 \mathrm{GPa}, E=190 \mathrm{GPa}$ ) taking into account the uncertainty in the optical determination of the diagonals $(2 \mu \mathrm{m})$ that would lead to about $7 \%$ and $5 \%$ uncertainty in Vickers hardness and Young's modulus, respectively.

Assuming $\epsilon=1$ in Eq. (5) to determine $h_{\mathrm{c}}$, the size of the projected area calculated from $h_{c}$ and the geometrical area-depth ratio of the indenter was $5790 \pm 40 \mu \mathrm{m}^{2}$. Using this value, the obtained Young's modulus (190 \pm $6 \mathrm{GPa}$ ) was similar to that determined from the optically determined areas.

The quality and repetitiveness of the curves obtained for this standard steel as well as the obtained Young's modulus and hardness values demonstrated the adequacy of both the specially developed instrumented microindenter and the method of analysis of the curves for the testing of materials.

\section{RESULTS AND DISCUSSION}

\section{A. Mlcrostructure and dynamle Young's modulus}

Characteristic microstructures of the studied materials are shown in Fig. 3; Table I lists the quantitative microstructural parameters together with the values of the dynamic Young's modulus. The six materials were dense ( $\rho>97 \%$ of theoretical) with small $(\leqslant 1 \mu \mathrm{m}$ ) pores at grain boundaries and triple points. In the composites, aluminium titanate was homogeneously distributed and located mainly at alumina triple points, and no titania was observed at this level (SEM). In the composite with the smallest grain size [Fig: 3(e)], small aluminium titanate grains were detected inside the alumina grains.

The three alumina materials presented different levels of microstructural development [Figs. 3(a)-3(d), Table I] from fine and homogeneous for P-A [Fig. 3(a)] to the 

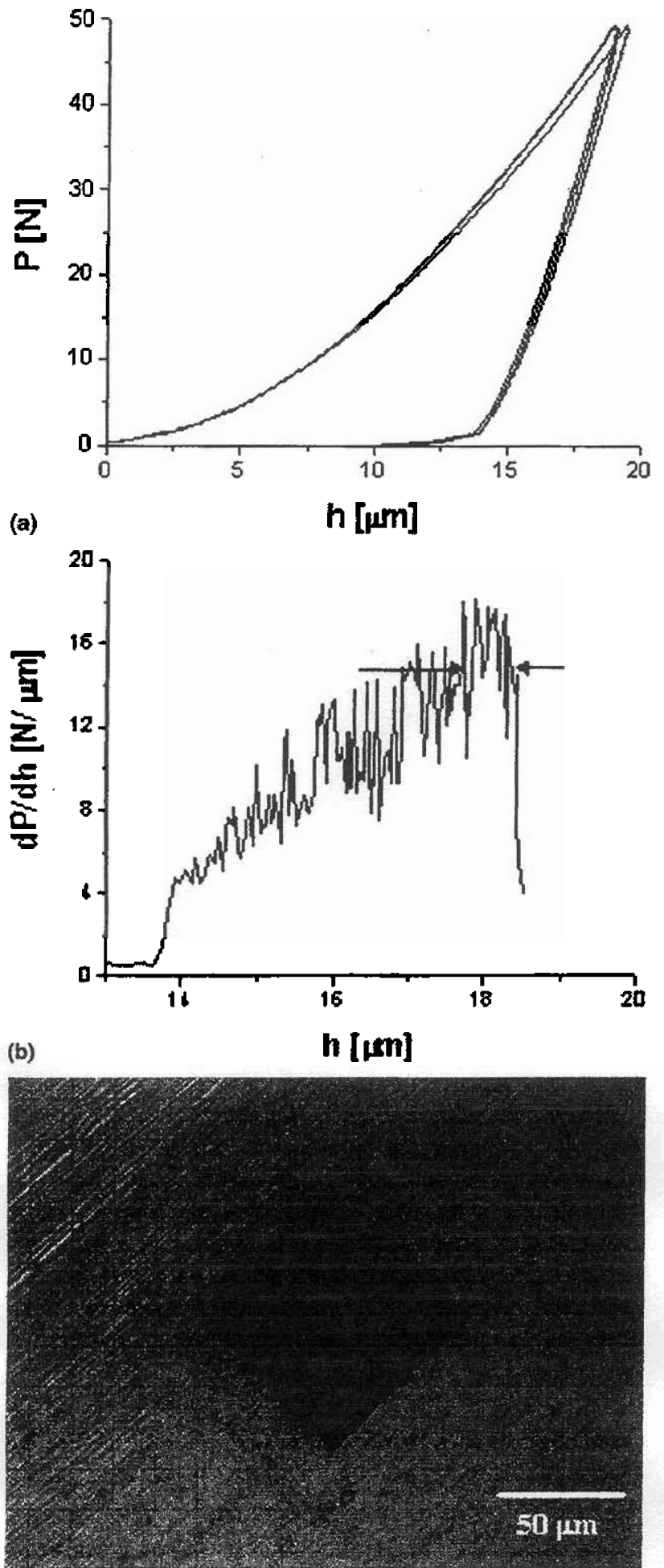

(c)

FIG. 2. Characteristic load-penetration depth curves for a standard steel analyzed to check validity of the method (a) and the respective derivative (b) during the unloading cycle. Arrows signal the interval for derivative averaging. (c) shows a characteristic residual impression. bimodal microstructure shown by S-A1550, with some grains larger than $10 \mu \mathrm{m}$ and the rest of the grains in the range described by the average size determined by the linear intercept method [Figs. 3(c) and 3(d)]. The material S-A1450 presented an intermediate microstructure [Fig. 3(b)]. Regarding the composites [Figs. 3(e)-3(g), Table $\Pi$, in material P-A10AT [Fig. 3(e)], the aluminium titanate grains had diameters below the minimum one $(\cong 2.2 \mu \mathrm{m})^{32}$ for spontaneous microcracking of the alumina matrix during cooling from the sintering temperature, whereas the other two [Figs. 3(f) and $3(\mathrm{~g})]$ had a significant number of grain sizes, and even the average in the case of S-A10AT-1550, larger than the critical one. Exaggerated grain growth of alumina did not occur in the composite sintered at the highest temperature [S-A10AT1550 , Fig. $3(\mathrm{~g})$, as occurred in the corresponding alumina material which showed the associated pore trapping [Figs. 3(c) and 3(d)], due to the inhibition of the grain growth of alumina by the presence of the second.phase.

There were no significant differences in the dynamic Young's modulus values as a function of grain size for each compositional series of materials once the slight differences in porosity are taken into account by using the general relationship:

$$
E=E_{0} \cdot \exp (-b \cdot P),
$$

where $E_{0}$ and $E$ are the Young's modulus of the materials with porosities zero and $P$, respectively, and $b=3$ for alumina materials with round pores ${ }^{34}$ Calculations using values from Table I give $E_{0}=413$ and $386 \mathrm{GPa}$, with standard deviations of 6 and $5 \mathrm{GPa}$ for the alumina materials and the composites, respectively. Results for the composites indicate that generalized spontaneous microcracking did not take place during cooling in the materials, even in those with aluminium titanate grain sizes in the critical range (S-A10AT-1450, 1550, Table I).

The microstructural and compositional differences between the materials described above were chosen because they would lead to different behaviors in terms of microcrack development under the highly localized loads involved in indentation testing, as observed by Guiberteau et al. ${ }^{35}$ for alumina materials subjected to Hertzian contact.

\section{B. Load-penetration depth curves and imprints}

Figure 4 shows characteristic experimental loadpenetration depth curves for the six materials. The curves were fairly coincident for different tests of the same material. The aspect of the indentation imprints is shown in Fig. 5.

To relate the obtained load-displacement curves with the aspect of the imprints, the extent of surface displacement at the contact perimeter was quantified using two different approaches. 

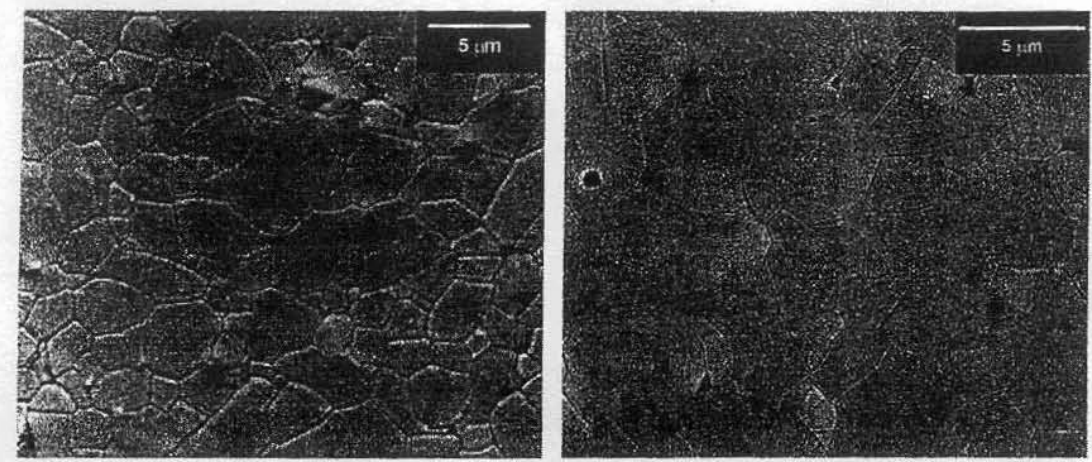

(a)

(b)
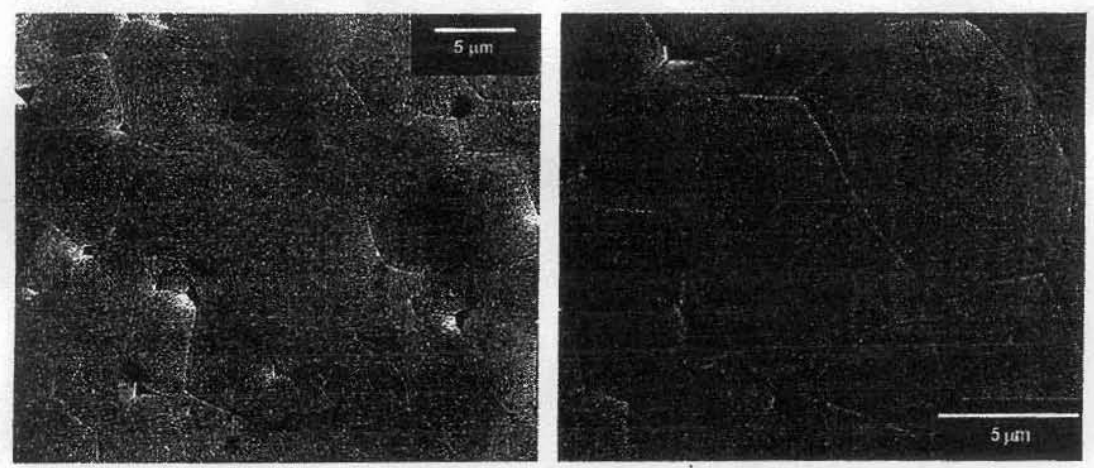

(c)

(d)
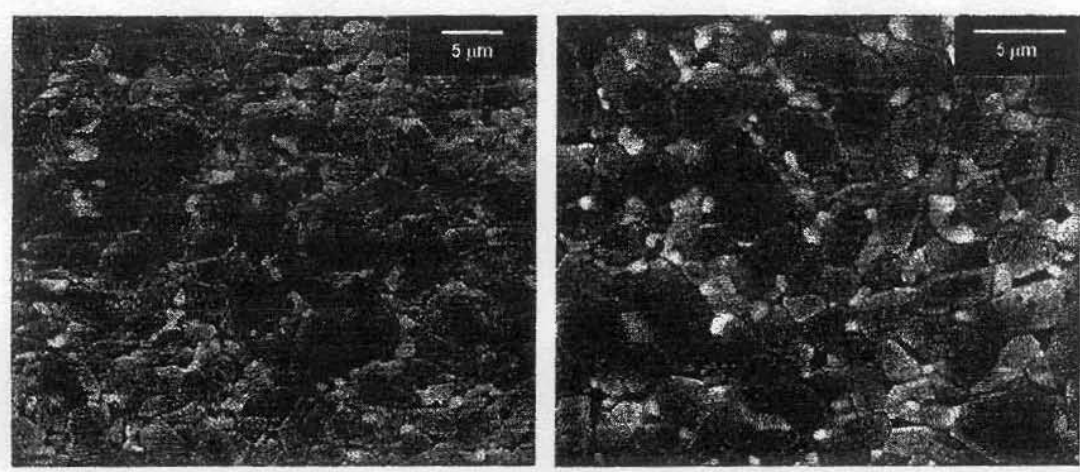

(e)

(f)

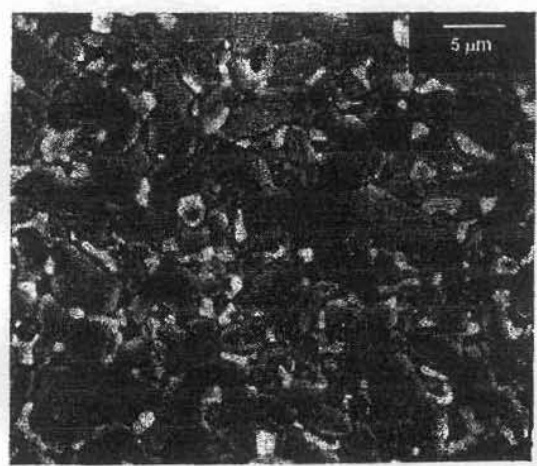

(g)

FIG. 3. Scanning electron micrographs of polished and thermally etched surfaces of the studied materials: (a) P-A. (b) S-A1450, (c) S-A1550, (d) detail of large grains in S-A1550, (e) P-A10AT, (f) S-A.10AT-1450, and (g) S-A10AT-1550. $\mathrm{Al}_{2} \mathrm{O}_{3}$ grains appear with dark gray color and $\mathrm{Al}_{2} \mathrm{TiO}_{5}$ of an intermediate gray shade. 
TABLE I. Properties of the materials ( $\rho$ : density, $G$ : grain size, $E:$ elastic modulus, A: Alumina, AT: Aluminium titanate; sd: standard deviation).

\begin{tabular}{lcccc}
\hline \hline & $\begin{array}{c}\rho(\mathrm{sd}) \\
(\% \text { th.) }\end{array}$ & $\begin{array}{c}G_{\mathrm{A}}(\mathrm{sd}) \\
(\mu \mathrm{m})\end{array}$ & $\begin{array}{c}G_{\mathrm{Ar}}(\mathrm{sd}) \\
(\mu \mathrm{m})\end{array}$ & $\begin{array}{c}E(\mathrm{sd}) \\
(\mathrm{GPa})\end{array}$ \\
\hline P-A & $98.8(0.3)$ & $1.3(0.2)$ & $\ldots$ & $405(2)$ \\
S-A1450 & $98.1(0.3)$ & $3.5(0.3)$ & $\ldots$ & $387(5)$ \\
S-A1550 & $98.1(0.5)$ & $5.5(0.5)$ & $\ldots$ & $388(5)$ \\
P-A10AT & $98.5(0.5)$ & $1.2(0.1)$ & $1.0(0.1)$ & $375(5)$ \\
S-A10AT-1450 & $97.3(0.5)$ & $3.2(0.4)$ & $2.2(0.1)$ & $355(4)$ \\
S-A10AT-1550 & $97.2(0.3)$ & $3.9(0.3)$ & $2.4(0.2)$ & $349(4)$ \\
\hline
\end{tabular}

Zeng et al. ${ }^{25}$ defined the factor $\beta$, called the surface displacement factor, as the ratio between the ideal projected contact area corresponding to ideal square contact and no material sinking-in or pileup, calculated from $h_{\max }$ and the geometrical indenter area-depth ratio, and the true projected contact area.

Alternatively, the surface displacement factor $\alpha$ proposed by Alcalá et al., ${ }^{7,36}$ is defined as:

$$
\alpha=\frac{K}{H \cdot f},
$$

where $H$ is the hardness, determined as the ratio between the peak indentation load and $A_{\text {op }} f$ is 24.50 for Vickers tips, and $\mathrm{K}$ is obtained by fitting Kick's law $\left(P=\mathrm{K} \cdot \boldsymbol{h}^{2}\right)$ to the loading segment of the curves.

For consistency, factors $\beta$ and $\alpha$ should be related as follows:

$$
\alpha \cong 1 / \beta
$$

Results of the optical parameters, hardness values, and $h_{\max }$ values, are summarized in Table II. The fitting constants $K$, determined from the curves in Fig. 4 , are summarized in Table III together with the values of $1 / \beta$ and $\alpha$. For each material, these latter values are coincident inside the variability limits, thus demonstrating the consistency of the loading curves.

For the alumina materials and the composite with the smallest grain size [Figs. 5(a)-5(d)], the shape of the imprints was not a perfect square; they were slightly deformed toward the centers, as usual in alumina ${ }^{1.25}$ and other ceramics, such as YTZP, ${ }^{23,25}$ in which elastic sinking-in occurs during loading and is partially recovered during unloading. ${ }^{25}$ Even though the imprints presented different levels of holes left by grains, mostly located at the inner part or at the corners, the edges were not cracked, and there was a continuous connection between the imprint and the remaining surface of the samples along the edges. This continuity allowed the elastic sinking-in to be fully recovered during unloading. In agreement with these observations, $\alpha$ values (Table III) were close to that evaluated for purely elastic materials
$(0.40)_{-}^{36}$ The $\alpha$ values were slightly lower than that determined from measurements of the surface displacement in other fine-grained alumina $\left(\alpha \cong 0.50\right.$ ), ${ }^{36}$ which can be due to differences in the method of determination of to the occurrence of non-elastic deformations in the altmina that presented higher $\alpha$.

Conversely, most of the holes left by grains were distributed along the edges in the specimens of the two composites with the largest grain sizes [Figs. 5(e) and $5(\mathrm{f})$, up to the point of lack of connection between the inner part of the imprint and the remaining surface of the material. This tangential cracking at the edges of the imprints has also been reported for highly textured $\alpha$ sialon ceramics. ${ }^{24} \mathrm{On}$ the other hand, the inner part of the imprints of the large grained alumina specimens was highly deteriorated [Fig. 5(c)]. Accordingly, $\alpha$ values for these three materials (Table III) were significantly lower than the limit for purely elastic behavior, revealing fracture under the indent.

In general, variability in maximum depth values $\left(h_{\max }\right.$, Fig. 4, Table II) was relatively low for all materials, except for the large grain sized alumina, which can be attributed to the fact that maximum penetration values for this material ( $\cong 20 \mu \mathrm{m}$ ) were only about twice the size of the largest grains $[\equiv 10 \mu \mathrm{m}$, Fig. 3(d)]. Values were significantly smaller for the alumina with the finest microstructure (P-A) than for the other materials, and they increased with grain size in each compositional series. The same tendency was followed by the true projected contact areas $A_{\text {op }}$ (Table II). Accordingly, hardness values $H$, calculated from maximum load and $A_{\mathrm{op}}$, decreased for increasing grain sizes (Table II), in opposition to general trends for materials. This apparent contradiction is explained by the different level of failures inside and at the edges of the imprints (Fig. 5) between the materials, partially quantified by the surface displacement factors (Table III).

As a first observation, the initial unloading in curves plotted in Fig. 4 are similar for the alumina materiais and the composite with the smallest grain size [Figs. 4(a)4(d)], on the one hand, and for the two composites with larger grain sizes, on the other [Figs. 4(e) and 4(f)]. For the latter, the curves are apparently linear or slightly concave up, such as those reported for different materials $^{6}$ and observed in this work for steel tested at the same load levels [Fig. 2(a)]. For the alumina materials, the curves present two regions with different concavity, with a distinct inflexion point. These observations are highlighted by the derivative of the curves (Fig. 6). For the two composites, a clear maximum is located just at the initiation of unloading, as occurred for steel [Fig. 2(b)], whereas for the other four materials, the maximum is displaced toward depth values $h_{\text {dermax }}$ lower than maximum depth (Table IV). These features of the curves indicate that unloading data are not described by a single 

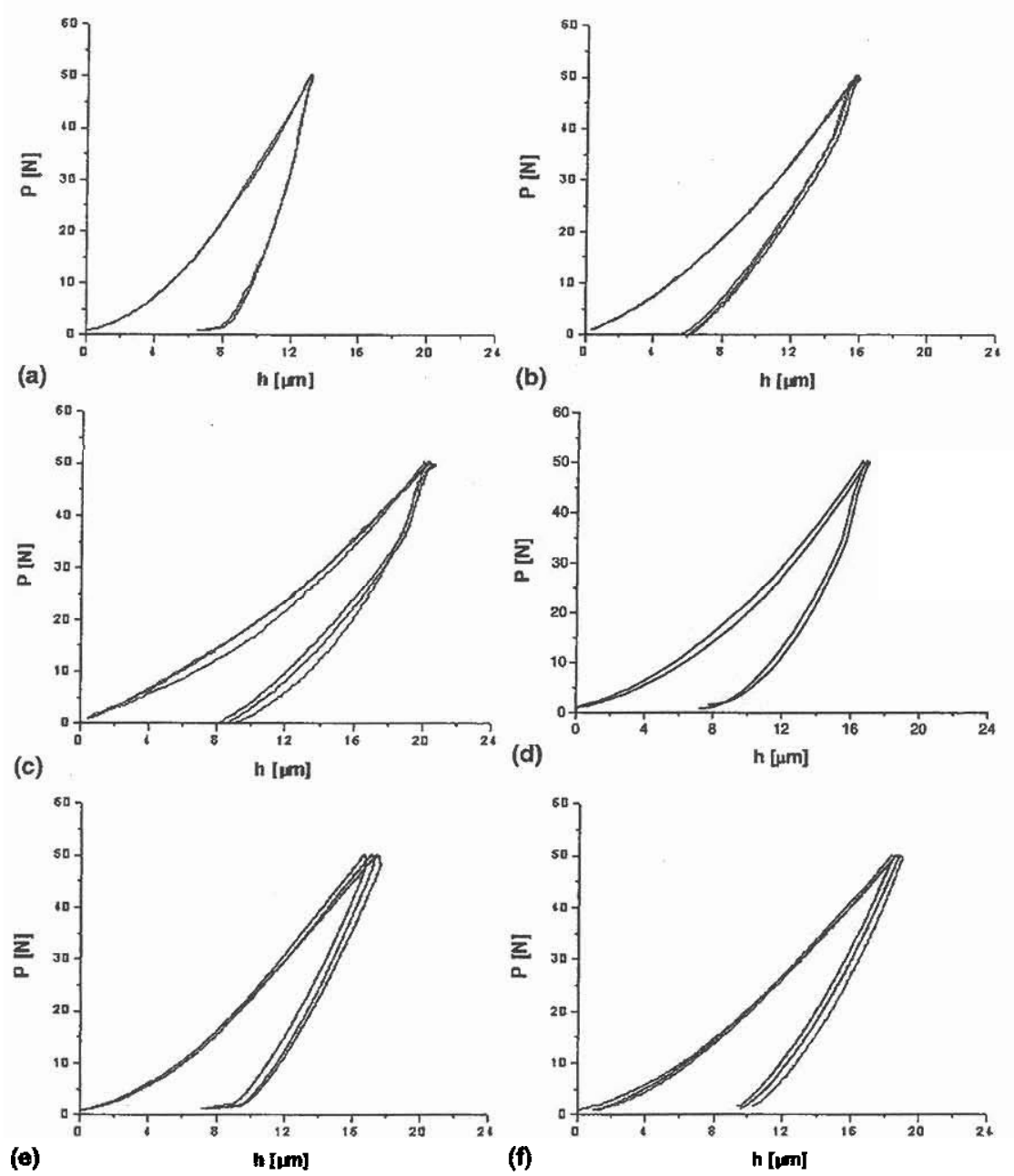

FIG. 4. Characteristic load-penetration depth curves. The curves comresponding to three different tests are plotted to show reliability: (a) P-A (only two curves are shown due to coincident patterns), (b) S-A1450, (c) S-A1550, (d) P-A10AT, (e) S-A10AT-1450, and (f) S-A10AT-1550.

power law fit, in a way similar to that of the data for mixed elastic-plastic contact. ${ }^{5}$ Therefore, determination of maximum stiffness $S$ was done by selecting the appropriate portion of the derivative curves (Fig. 6) individually and calculating the mean values of the derivates in this interval.

As shown in Fig. 6, the selection of the curve portions was straightforward for the fine-grained materials and for the coarse alumina [Figs. 6(a)-6(d)]. For the two composites with large grain size, the interval was not so clear [Figs. 6(e)-6(f)]. Nevertheless, the decrease of stiffness values was very smooth and, consequently, different portions of the curves could be chosen without a significant change in $S$ values. For instance, to take an interval $1 \mu \mathrm{m}$ larger than the one marked in Figs. 6(e) and 6(f) would lead to $S$ values less than $10 \%$ lower than those in Table IV. For these materials, portions of the curves for which the standard deviations for $S(\cong 8 \%)$ were smaller than $10 \%$ were chosen.
Values of maximum stiffness decreased with alumina grain size increase, especially for the monophase materials (Tables I and IV). Again, this parameter showed larger variability for coarser microstructures.

Due to the lack of single power fit law found in this work (Fig. 6), $m$ values could not be determined, and $h_{\mathrm{c}}$ values were calculated assuming the flat punch geometry, $\epsilon=1$ in Eq. (5). This would lead to slightly lower values for $h_{\mathrm{c}}$ and the projected contact area ${ }^{6}$ and, consequently, higher Young's modulus values $(\approx 3-10 \%$ for the order of values of this work and $\epsilon=0.75$ ). From $h_{c}$ values and considering the indenter geometry, the contact area values $A_{c}$ were calculated (Table IV).

Standard deviation values for $A_{\mathrm{op}}$ (Table II) were much lower than those for $A_{c}$ (Table IV). This difference is due to differences in the experimental parameters used for calculation, the diagonal of the imprints $2 a$ and the contact depth $h_{c}$ for $A_{\mathrm{op}}$ and $A_{c}$, respectively. The experimental variability associated to the former 


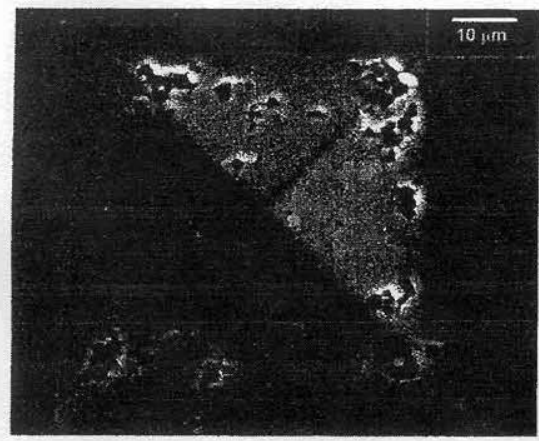

(a)

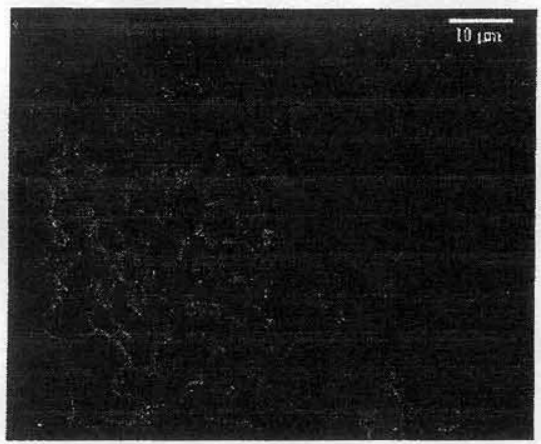

(c)

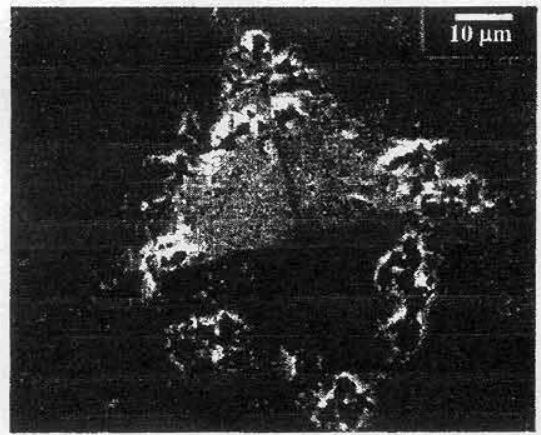

(e)

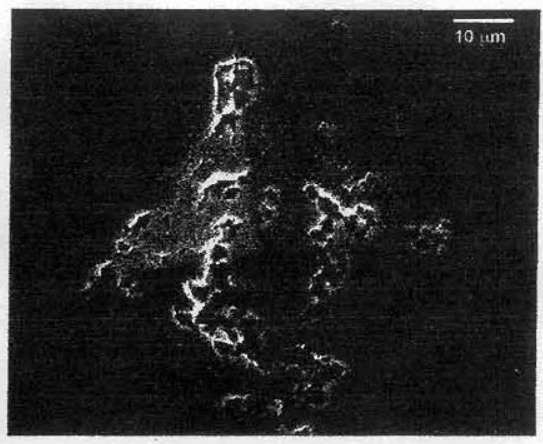

(b)

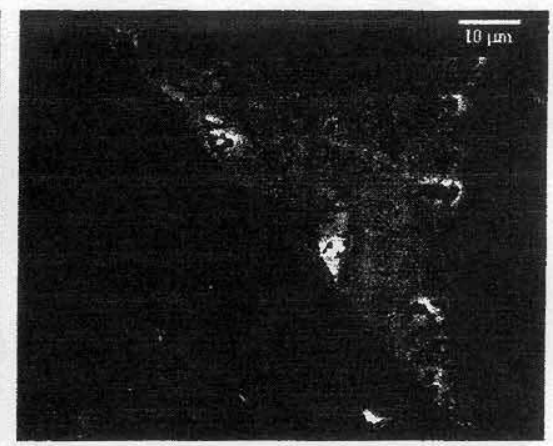

(d)

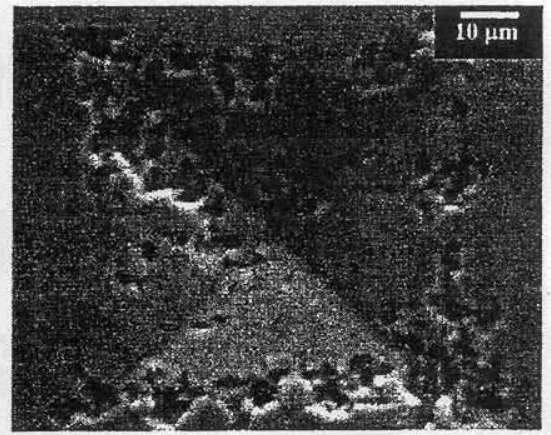

(f)

FIG. 5. Characteristic residual impressions of the indentation tests ( $50 \mathrm{~N}$ ) for the six studied materials: (a) P-A, (b) S-A1450, (c) S-A1550, (d) P-A10AT, (e) S-A10AT-1450, and (f) S-AI0AT-1550. Scanning electron micrographs show polished and indented surfaces.

parameter ( $\leqslant 3 \%$, Table II) has very little effect in the calculated true projected contact area $A_{\mathrm{op}}$. The major problem related with $A_{\mathrm{c}}$ is that $h_{\mathrm{c}}$ values (Table IV) are comparable to the microstructural parameters (Table $\mathrm{I}$ ) and, therefore, $A_{c}$ is extremely affected by variations in the experimental parameter used for its determination, $h_{c}$, smaller than the microstructural parameters of the materials. Consequently, it seems more reasonable to use the optical contact area to characterize the behavior of materials under indentation loads that lead to contact depths comparable to the microstructure. The average values of $A_{\text {op }}$ were similar to those determined from $h_{c}$ for five of the studied materials (P-A, P-A10AT, S-A1450,
TABLE II. Numerical parameters corresponding to the optical observations of residual impressions (Fig. 5; a, half-diagonal of the imprint; $A_{o p}$, true projected contact area calculated from $2 a$ measured optically; $H$, hardness) and maximum depth in Fig. 4. (sd, standard deviation).

\begin{tabular}{lcccc}
\hline \hline & $\begin{array}{c}2 a(\mathrm{sd}) \\
(\mu \mathrm{m})\end{array}$ & $\begin{array}{c}A_{\text {op }}(\mathrm{sd}) \\
\left(\mu \mathrm{m}^{2}\right)\end{array}$ & $\begin{array}{c}H(\mathrm{sd}) \\
(\mathrm{GPa})\end{array}$ & $\begin{array}{c}h_{\max } \\
(\mathrm{sd})(\mu \mathrm{m})\end{array}$ \\
\hline P-A & $69(0)$ & $2408(0)$ & $21.1(0.2)$ & $13.2(0.1)$ \\
S-A1450 & $76(0)$ & $2888(0)$ & $17.3(0.1)$ & $15.8(0.1)$ \\
S-A1550 & $78(2)$ & $3036(136)$ & $16.8(1.2)$ & $20.6(0.5)$ \\
P-A10AT & $76(2)$ & $2884(129)$ & $17.3(0.6)$ & $16.9(0.1)$ \\
S-A10AT-1450 & $80(2)$ & $3205(137)$ & $15.6(0.6)$ & $17.3(0.2)$ \\
S-A10AT-1550 & $80(2)$ & $3228(142)$ & $15.5(0.7)$ & $18.1(0.1)$ \\
\hline \hline
\end{tabular}


TABLE III. Surface displacement due to sinking-in; $\beta$, surface displacement factor; $K$, constant in Kick's Law; $\alpha$, surface displacement factor (Eq. 7). For consistency $\alpha$ should be equal to $1 / \beta$. (sd, standard deviation.)

\begin{tabular}{llcc}
\hline \hline & $1 / \beta(\mathrm{sd})$ & $\mathrm{K}(\mathrm{sd}) \mathrm{GPa}$ & $\alpha(\mathrm{sd})$ \\
\hline P-A & $0.45(0.02)$ & $222(4)$ & $0.43(0.02)$ \\
S-A1450 & $0.40(0.03)$ & $157(6)$ & $0.37(0.03)$ \\
S-A1550 & $0.30(0.1)$ & $91(13)$ & $0.22(0.04)$ \\
P-A10AT & $0.35(0.02)$ & $147(18)$ & $0.35(0.03)$ \\
S-A10AT-1450 & $0.33(0.03)$ & $101(9)$ & $0.26(0.03)$ \\
S-A10AT-1550 & $0.27(0.02)$ & $80(7)$ & $0.22(0.03)$ \\
\hline
\end{tabular}

S-A10AT-1450, and S-A10AT-1550). Differences were the largest for the large grain sized alumina (S-A1550), for which $h_{\mathrm{c}}$ values ( $\cong 15 \mu \mathrm{m}$, Table IV) were about three times the size of the largest grains [>5 $\mu \mathrm{m}$, Fig. 3(d)].

\section{YOUNG'S MODULUS DETERMINED FROM THE LOAD-DISPLACEMENT CURVES AND MICROCRACKING}

The values for the Young's modulus, $E_{\mathrm{op}}$ and $E_{\mathrm{c}}$ calculated from the stiffness values ( $S$, Table IV) and $A_{\text {op }}$ and $A_{c}$ (Tables II and IV), using Eq. (1) are summarized in Table V. For each material, average values of $E_{\mathrm{c}}$ were lower than those for $E_{\mathrm{op}}$. This difference was significant with respect to the experimental variability only for the alumina with the coarsest microstructure, for which $A_{\varepsilon}$ was much larger than $A_{\text {op }}$ (Tables II and IV).

Young's modulus values determined by indentation tests were significantly lower than the dynamic ones (Tables I and IV), which, in principle, could be related to microcrack damage of the studied materials during testing.

The Young's modulus of a microcracked material $E$ can be related to that of the material without microcracks $E_{0}$ using a simple classical model ${ }^{37}$ that considers the volumetric density of microcracks $N$ of equal radius $l$. In this model:

$$
E=E_{0} \cdot\left(1+\frac{16 \cdot\left(1-v^{2}\right) \cdot N \cdot l^{3}}{9 \cdot(1-2 v)}\right)^{-1},
$$

where $v$ is the Poisson's ratio of the material.

The unloading data obtained for the three alumina materials and the composite with the finest microstructure [Figs. 4(a)-4(d)] were not described by a single power law fit. Maximum stiffness for these materials was reached at depth values $h_{\text {dermax }}$, smaller than $h_{\max }$, which would indicate an increase of contact surface at the initial part of the unloading cycle. Even though this aspect has not been underlined in previous papers, it is similar to that of the curves shown by other authors for a number of structural ceramics tested with Vickers microindenters at relatively high loads $(\cong 50$ to $80 \mathrm{~N}$ ). In particular, such a shape is observed in the initial part of the unloading curves shown by Alcalá ${ }^{23}$ for fine-grained Mg-PSZ and ytria-doped tetragonal zirconia (YTZP), in which an expansive transformation occurs under the indent, and in the curves from Zeng et al, ${ }^{25}$ for $\mathrm{MgO}$ and $\mathrm{MgAl}_{2} \mathrm{O}_{4}$, in which some extent of microcracking might take place under the indenter. Conversely, it is not apparent in the curves shown by the former authors ${ }^{23}$ for nontransforming annealed magnesia partially stabilized zirconia (Mg-PSZ). ${ }^{23}$ Moreover, it has not been observed here for steel tested under the same experimental conditions [Figs. 2(a) and 2(b)].

As noted by Mencik et al., ${ }^{10}$ the shape of the unloading curve might be influenced by the onset of cracking or phase transformations. In this sense, an expansion of the material under the indent upon unloading due to the opening of microcracks would lead to an increase of the contact area and, consequently, of the stiffness at the initiation of unloading.

Microcracks have been reported to develop during unloading from those nucleated at grain boundaries during loading in alumina materials subjected to Hertzian contact by Guiberteau et al. ${ }^{35}$ According to these authors, microcrack pop-in occurs during the loading half-cycle from shear faults inside the grains. As microcracks are subjected to intense constraining hydrostatic compression at full load, they stop at the grain boundaries, and their opening occurs stably on release of the compression during unloading. As the stress intensity factor of the shear faults is determined by the grain size, the level of microcracking in the material should be determined by the grain size, as observed in their work.

If a process similar to that reported for alumina materials under Hertzian contact occurred in the studied materials under Vickers indentation and was responsible for the inverse curvature of the unloading curves [Figs. 4(a)4(d)], the level of microcracking in the materials should be determined by the alumina grain size. Moreover, even though the exact value of $\mathrm{Nl}^{3}$ will change continuously upon the removal of the indenter and will be affected, not only by the volume of microcracks, but also by the internal friction between them, it should be possible to establish a relationship between the expansion of the materials under the indenter upon unloading due to microcrack opening and $\mathrm{Nl}^{3}$. To test this hypothesis, $\mathrm{Nl}^{3}$ for equal volumes of material tested was evaluated using Eq. (9) taking microindentation and dynamic Young's modulus values as $E$ and $E_{0}$, respectively.

In Fig. 7(a), the calculated $N l^{3}$ values are plotted versus the alumina grain size. For each series of materials, alumina and composites, the density of microcracks increased with alumina grain size, as observed by Guiberteau et al., ${ }^{35}$ indicating that the alumina grain size determined the level of microcracking in the materials. 

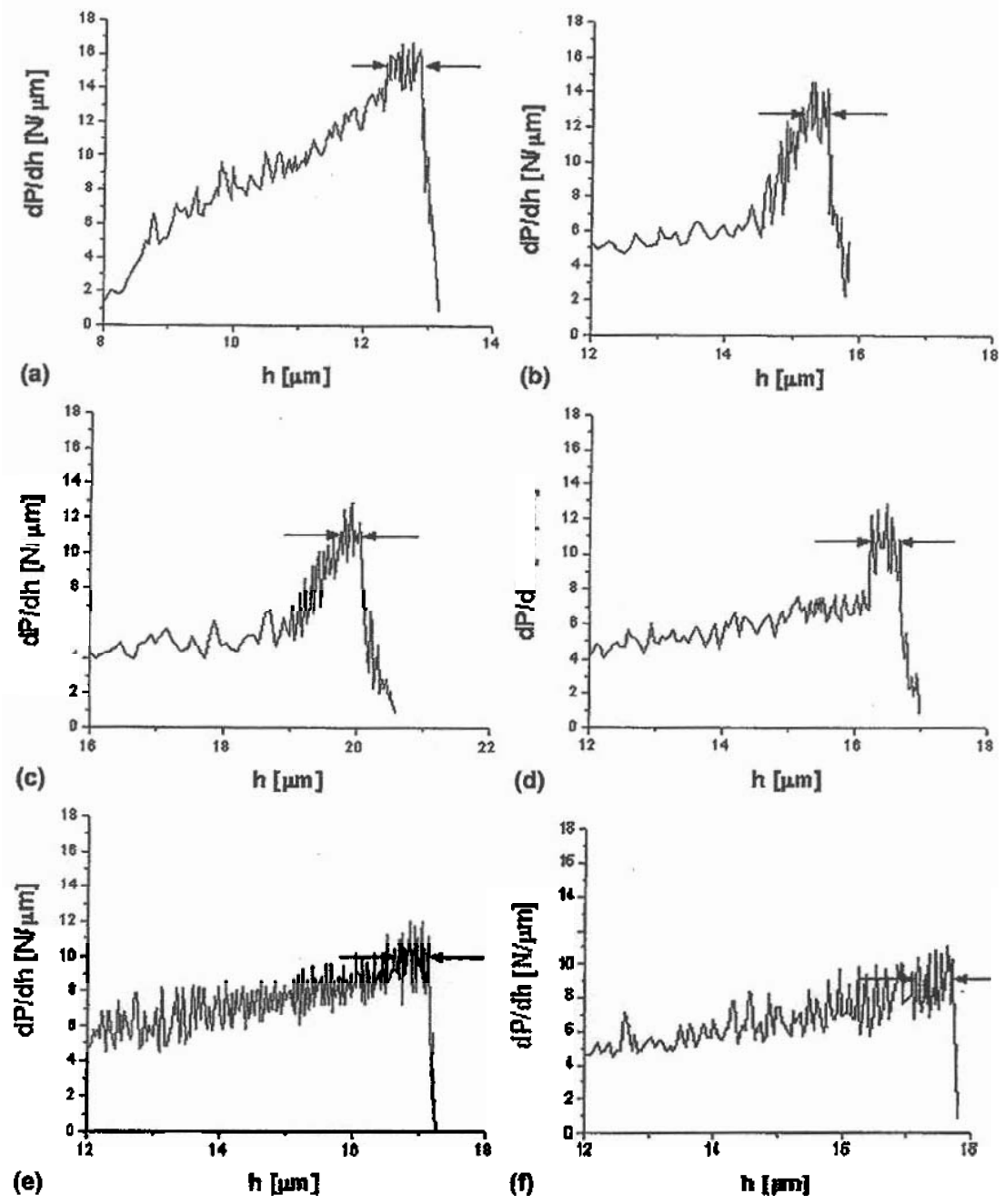

FIG. 6. Characteristic derivative curves of the experimental load-depth curves (Fig. 4) during the unloading cycle: (a) P-A, (b) S-A1450, (c) S-A1550, (d) P-A 10AT, (c) S-A10AT-1450, and (f) S-A10AT-1550. Arrows indicate the interval for derivative averaging.

TABLE IV. Numerical parameters of the load-penetration depth curves and the derivatives (Figs. 4 and 6 ); $h_{\text {derrox }}$ and $S$, depth for maximum derivative and maximum contact stiffness; $h_{\mathrm{c}}$, contact depth, and $A_{c}$ contact area calculated from $h_{c}$ (sd: standard deviation.)

\begin{tabular}{lcccc}
\hline \hline & $\begin{array}{c}h_{\text {dermex }} \text { (sd) } \\
\mu \mathrm{m}\end{array}$ & $\begin{array}{c}S(\mathrm{sd}) \\
\mathrm{N} / \mu \mathrm{m}\end{array}$ & $\begin{array}{c}h_{c} \text { (sd) } \\
\mu \mathrm{m}\end{array}$ & $\begin{array}{c}A_{\mathrm{c}} \text { (sd) } \\
\mu \mathrm{m}^{2}\end{array}$ \\
\hline P-A & $12.8(0.1)$ & $15.2(0.1)$ & $10.1(0.4)$ & $2502(203)$ \\
S-A1450 & $15.2(0.1)$ & $12.3(0.8)$ & $11.5(0.5)$ & $3219(259)$ \\
S-A1550 & $19.9(0.7)$ & $11.2(1.2)$ & $15.5(0.5)$ & $5917(381)$ \\
P-A10AT & $16.5(0.1)$ & $10.8(0.6)$ & $12.0(0.3)$ & $3528(119)$ \\
S-A10AT-1450 & $\cdots$ & $8.8(0.6)$ & $11.8(0.6)$ & $3429(373)$ \\
S-A10AT-1550 & $\cdots$ & $8.0(1.0)$ & $11.8(1.0)$ & $3430(509)$ \\
\hline \hline
\end{tabular}

The opening of the microcracks, which depends critically on the residual stresses and the grain size, should be more effective in the composite materials with coarser microstructures (S-A10AT-1450 and S-A10AT-1550, Table I), which explains the crack densities for the three
TABLE V. Young's modulus calculated from maximum stiffness $S$ and from the contact areas $A_{\mathrm{c}}$ and $A_{\mathrm{op}}$ from Tables II and IV. (sd: standard deviation.)

\begin{tabular}{lcc}
\hline \hline & $E_{\text {op }}(\mathrm{sd})(\mathrm{GPa})$ & $E_{\mathrm{c}}(\mathrm{sd})(\mathrm{GPa})$ \\
\hline P-A & $347(6)$ & $340(19)$ \\
S-A1450 & $239(21)$ & $219(9)$ \\
S-A1550 & $212(21)$ & $144(15)$ \\
P-A 10AT & $202(19)$ & $175(13)$ \\
S-A10AT-1450 & $158(9)$ & $141(10)$ \\
S-A10AT-1550 & $135(16)$ & $129(14)$ \\
\hline \hline
\end{tabular}

composite materials found to be significantly higher than that of the aluminas [Fig. 7(a)]. Nevertheless, the unloading curves for these materials did not exhibit the inverse concavity, which should be attributed to the edge cracks [Figs. 5(e) and 5(f)] that would admit the expansion due to microcrack opening, avoiding the displacement of the surface under the imprint. 


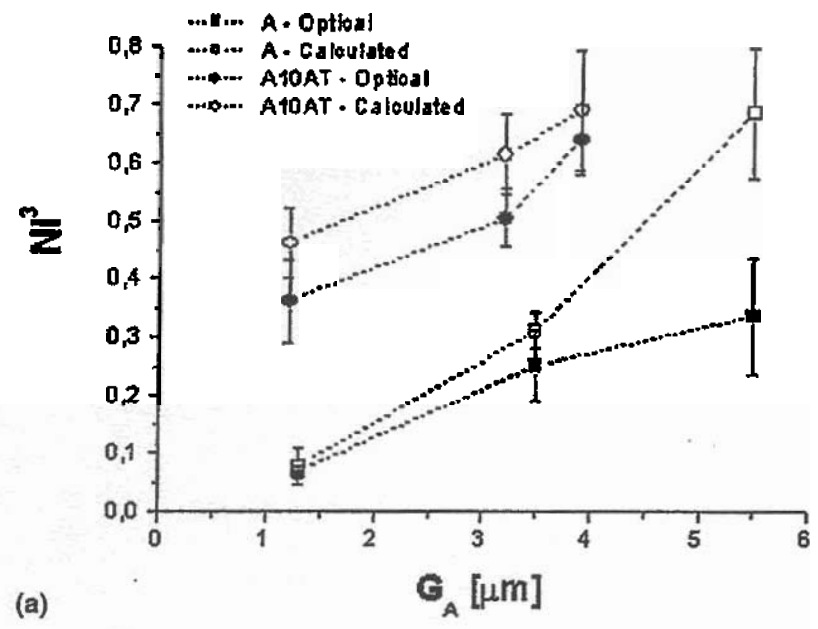

Fig. 7(b), this linear relationship is found for crack density values calculated from the values of Young's modulus determined using the contact area measured optically $E_{\mathrm{op}}$ and not when the contact area determined from $h_{\mathrm{c}}$ is used. This result further supports the above discussion on the better adequacy of $A_{\mathrm{op}}$ as compared to $A_{c}$ to characterize the materials. Even though similarities between grain size and the parameters $h_{\max }$ and $h_{\text {dermax }}$ will also affect their values, the effect will follow the same trend for both of them and thus will not affect $\Delta h$.

\section{CONCLUSIONS}

The adequacy of depth-sensing indentation tests in the micrometer range together with observations of the imprints to characterize alumina-based materials with different levels of residual stresses and grain sizes was analyzed.

The significant differences between the values of Young's modulus determined for different materials, as well as the definite relationships found between the microstructural parameters of the materials and the obtained Young's modulus values, demonstrate the adequacy of the method to analyze the behavior of materials with residual stresses under concentrated loads.

However, the Young's modulus values obtained have to be considered as parameters that quantify the amount of damage experienced by the materials and cannot be used to describe the elastic behavior of the materials subjected to different loading configurations.

(b)

$$
\Delta h^{3}\left[\mu \mathrm{m}^{3}\right]
$$

FlG. 7. Relationships between the calculated volumetric density of microcracks $N l^{3}$ versus the mean grain size of alumina $\left[G_{A}\right.$, Fig. $\left.7(a)\right]$ and versus the volumetric expansion of the material under the indenter due to microcracking [ $\Delta h^{3}, \mathrm{Fig}$. $\left.7(\mathrm{~b})\right]$. Square and round symbois refer to monophase aluminas and composites respectively; closed and open symbols refer to $N l^{3}$ calculated considering $E_{\text {op }}$ and $E_{c}$ in Table $\mathrm{V}$, tespectively.

In the alumina specimens, in which there was continuity between the indentation imprint and the remaining surface of the material [P-A, S-A1450, S-A1550, Figs. 5(a)-5(c)], expansion of the material under the indenter upon unloading should be related to differences between $h_{\max }$ and $h_{\text {dermax }}$ (Tables II and IV). The former parameter would correspond to the stage where only microcrack nucleation has taken place during loading whereas when $h_{\text {dermax }}$ is reached, maximum expansion has occurred. The volumetric differences between the stages of microcrack nucleation and complete microcrack opening will be proportional to the factor $(\Delta h)^{3}=$ $\left(h_{\max }-h_{\text {dermax }}\right)^{3}$. Thus, there should be a linear relationship between $\mathrm{Nl}^{3}$ and the volumetric expansion due to microcracking, proportional to $(\Delta h)^{3}$. As shown in

\section{ACKNOWLEDGMENTS}

The work was supported in part by the European Community's Human Potential Programme under Contract No. HPRN-CT-2002-00203 (SICMAC), by Project Nos. CICYT MAT2003-00836 and CAM GRMAT0707-2004, and by Grant No. CSIC I3P-BPD2001-1 (Spain).

\section{REFERENCES}

1. G.R. Anstis, P. Chantikul, B.R. Lawn, and D.B. Marshall: A critical evaluation of indentation techniques for measuring fracture toughness: I. Direct crack measurements, J. Ant. Cerant Soc. 64, 533 (1981).

2. B.R. Lawn, A.G. Evans, and D.B. Marshall: Elastic/plastic indentation damage in ceramics: The median/radial crack system. J. Am. Ceram Soc. 63, 574 (I980).

3. O. Sbaizero and E. Lucchini: Influence of residual stresses on the mecharical properties of a layered ceramic composite. J. Eur. Ceram. Soc. 16, 813 (1996).

4. R. Sathyamoorthy, A.V. Virkar, and R.A. Cutler: Damageresistance SiC-AlN layered composites with surface compressive stresses. J. Am. Cenam. Soc. 75, 1136 (1992).

5. S.P. Baker. The analysis of depth-sensing indentation data, in Thin Films: Stresses and Mechanical Properties $N$, edited by 
P.H. Townsend, T.P. Wejhs. J.E. Sancher, $J r$ and P. Borgesen (Mater Res Soc. Symp. Proc, 308, Pittsburgh, PA, 1993), p. 209.

6. W.C. Oliver and G.M. Pharr: An improver technique for determining hardness and elastic modulus using load and displacement sensing indentation experiments. J. Mater. Res. 7, 1564 (1992).

7. M. Mata and J. Alcalá: Mechanical property evaluation through sharp indentations in elastoplastic and fully plastic contact regimes. J. Mater. Res. 18, 1705 (2003).

8. T.J. Bell, A. Bendeli, J.S. Field, M.V. Swain, and E.G. Thwaite: The determination of surface plastic and elastic properties by ultra micro-indentation. Metrologia 28, 463 (1991/92).

9. G.M. Pharr, W.C. Oliver, and D.R. Clarke: Hysteresis and discontinuity in the indentation Ioad-displacement behavior of silicon. Scripla Metall. 23, 1949 (1989).

10. J. Mencik and M.V. Swain: Errors associated with depth-sensing microindentation tests. J. Mater. Res. 10, 1491 (1995).

11. X.M. Chen, A.W. Ruff, and J.W. Dally: A hybrid method for determining material properties from instrumented microindentation experiments. J. Mater. Res. 9, 1314 (1994).

12. D.L. Joslin and W.C. Oliver: A new method for analyzing data from continuous depth-sensing microindentation tests. J. Mafer. Res. 5, 123 (1990).

13. G.M. Pharr, W.C. Oliver, and F.R. Brotzen: On the generality of the relationship among contact stiffess, contact area, and elastic modulas during indentation. J. Mater. Res. 7, 613 (1992).

14. K.O. Kese, Z.C. Li, and B. Bergman: Influence of residual stress on elastic modulus and hardness of soda-lime glass measured by nanoindentation. J. Mater. Res. 19, 3109 (2004).

15. Y. Jung, B.R, Lawn, M. Martyniuk, H. Huang, and X.Z. Hu; Evaluation of elastic modulus and hardness of thin films by nanoindentation. J. Mater. Res. 19, 3076 (2004).

16. Z. Peng, J. Gong, and H. Miao: On the description of indentation size effect in hardness testing for ceramics: Analysis of the nanoindentation data. J. Eur. Ceram. Soc. 24, 2193 (2004).

17. Y. Choi. H. Lee. and D. Kwuon; Anatysis of sharp-tip-indentation load-depth curve for contact area determination taking into account pile-up and sink-in effects. J. Mater. Res. 19, 3307 (2004).

18. W.C. Oliver and G,M. Pharr: Measurement of hardness and elastic modulus by instrumented indentation: Advances in understanding and retuluenets to methodology. J. Mater. Res. 19, 3 (2004).

19. J.S. Field and M.V. Swain: Determining the mechanical properties of small volumes of material from submictometer spherical indentations. J. Mater. Res, 10, 101 (1995).

20. J.D. Schall and D.W. Brenner. Atomistic simulation of the influence of pre-existing stress on the interpretation of nanoindentation data. J. Mater. Res. 19, 3172 (2004).

21. S. Stresh, A.E. Giannakopoulos, and J. Alcalá: Spherical indentation of compositionally graded materials: Theory and experiments. Acta Mater, 45, 1307 (1997).
22. J. Alcala, A.E. Giannakopoulos, and S. Suresh: Continuous measurements of load penetration curves with spherical microindenters and the estimation of mechanical properties. J. Mater. Res. 13, 1390 (1998).

23. J. Alcalá: Instrumented microindentation of zirconia ceramics. J. Am. Ceram, Soc. 83, 1977 (2000).

24. Z.H. Xie, M. Hoffman, R.J. Moon, P.R. Munroe, and Y.B. Cheng: Subsurface indentation damage and mechanical characterization of $\alpha$-sialon ceramics. J. Am. Ceram. Soc: 87, 2114 (2004).

25. K. Zeng, E. Söderlund, A.E. Giannakopoulos, and DJ. Rowcliffe: Controlled indentation: A general approach to determine mechanical properties of brittle materials. Acta Mater. 44, 1127 (1996).

26. M.F. Doerner and W.D. Nix: A method for interpreting the data from depth-sensing indentation instruments. J. Mater. Res. 1, 601 (1986).

27. C. Baudín, F. Cambier, and L. Delaey: Fractographic and acouscic emission studies of mullite-alumina zirconia composites prepared by reaction sintering. J. Mater. Sci. 22, 4398 (1987).

28. R.F. Cook and G.M. Pharr: Direct observation and analysis of indentation cracking in glasses and ceramics. J. Am. Ceram. Soc. 73, 787 (1990).

29. D. Taylor: Themmal expansion data: III. Sesquioxides, $\mathrm{M}_{2} \mathrm{O}_{3}$ with the corundum and the $\mathrm{A}-\mathrm{B}$ - and $\mathrm{C}-\mathrm{M}_{2} \mathrm{O}_{3}$ structures. $\mathrm{Br}$. Ceram. Trans. J. 83, 92 (1984).

30. D. Taylor: Thermal expansion data. XI. Complex oxides, $\mathrm{A}_{2} \mathrm{BO}_{5}$, and the gamets, Brit. Cer. Trans, J. 86, 1 (1987).

31. F.E. Buresch, K. Frye, and Th. Mäller: Relationships between microcrack zones and toughness of fine grained alumina and coarse grained graphite, in Fracture Mechanics of Ceramics, 5, Surface Flaws, Statistics and Microcracking, edited by R.C. Bradt, A.G. Evans, D.P.H. Hasselman, and F.F. Lange (Plenum Press, New York, NY, 1983), p. 591.

32. $R$. Uribe and $C$. Baldín: Influence of a dispersion of aluminium itanate particles of controlled size on the thermal shock resistance of alumina. J. Am. Ceram. Soc. 86, 846 (2003).

33. $\mathrm{S}$. Bueno, R. Moreno, and C. Baudín: Reaction sintered $\mathrm{Al}_{2} \mathrm{O}_{3} /$ $\mathrm{Al}_{2} \mathrm{TiO}_{5}$ microcrack-free composites obtained by colloidal filtration. J. Eur. Ceram. Soc. 24, 2785 (2004).

34. R.A. Penty, D.P.H. Hasselman, and M. Spriggs: Young's modulus of high density polycrystalline mullite. J. Am. Ceram. Soc. 55, 169 (1972).

35. F. Guiberteau, N.P. Padture, and B.R. Lawn: Effect of grain size on Hertzian contact damage in alumina. J. AmL Ceram Soc. 77, 1825 (1994).

36. J. Alcalá, A.C. Barone, and M. Anglada: The influence of plastic hardening on surface deformation modes around Vickers and spherical indents. Acta Mater. 48, 3451 (2000).

37. I.B. Walsh: The effect of cracks on the compressibility of rock. J. Geophys. Res. 70, 381 (1965). 